\title{
Long-term retention of information about presentation modality by children and adults
}

\author{
ELYSE BRAUCH LEHMAN, JAMES W. MIKESELL, and SUZANNE C. DOHERTY \\ George Mason University, Fairfax, Virginia
}

\begin{abstract}
A mixed-modality continuous recognition task followed by a final recognition test after $0 \mathrm{~h}$, $4 \mathrm{~h}, 1$ day, or 7 days was administered to third- and fourth-grade children and adults. Subjects gave recognition responses and reported presentation modalities. Forgetting rates for both words and input mode were invariant with age. The decay functions for presentation modality were affected, however, by the initial input mode, with modality identification declining more rapidly for words heard first than for words seen first. Information about whether a word was seen or heard remained in memory for at least $4 \mathrm{~h}$. The results demonstrate that long-term-memory representations contain a great deal of information about input mode and suggest that the theoretical distinction between automatic and effortful processing may be a useful one.
\end{abstract}

Little is known about the long-term retention of contextual information in children and adults. Although scattered instances in the literature indicate that these features can be recovered even a year after initial presentation (Kolers, 1975, 1976), there is still much to be learned about the decay functions themselves and about the factors that affect these functions.

The present studies focus on memory for a particular aspect of context, that is, presentation modality. Evidence that representations contain a great deal of information about whether words are seen or heard is accumulating. For instance, it has been shown clearly that college students retain input mode for at least $15 \mathrm{~min}$ after presentation whether or not they have been told beforehand to remember it (Bray \& Batchelder, 1972; Hintzman, Block, \& Inskeep, 1972; Kirsner, 1974; Madigan \& Doherty, 1972). More recently, Lehman and Hanzel (1981) demonstrated that children also readily store information about whether a word has been seen or heard and that they do so as well as young adults. Accuracy levels for modality identification, in fact, often exceed $70 \%$.

These studies do not, however, provide a complete picture of the decay course of modality information. What is needed are retention intervals longer than the $15 \mathrm{~min}$

Portions of this paper were presented at the meeting of the Eastern Psychological Association, Baltimore, MD, April 1984. We wish to thank the teachers, parents, and students who participated in our study and the following directors who helped us work in their schools: Betsy Edwards and Julie Cantagna, Sunrise Valley Country Day School, Vienna, VA; Fred Lowry, Kiddie Country Children's Development and Learning Center, Burke, VA; Mrs. Bauer, Talent House, Fairfax, VA; Barbara Katz, Town and Country School, Vienna, VA. J. W. Mikesell's present address is: Henderson Human Development Building, Pennsylvania State University, University Park, PA 16870 . S. C. Doherty's present address is: Tri-County Youth Services Bureau, Charlotte Hall, MD 20622. Requests for reprints should be addressed to: Elyse B. Lehman, Department of Psychology, George Mason University, 4400 University Drive, Fairfax, VA 22030. used by Bray and Batchelder (1972). The present studies rectify this situation by including retention intervals of up to 7 days. Three questions were asked. (1) How long does modality information last (what is its decay rate)? (2) Is it lost more rapidly by children than by adults? (3) Is it lost more rapidly than the semantic features of words?

The obtained decay functions add to a small group of developmental studies on forgetting. This research suggests that forgetting rates for semantic information (i.e., for words, pictures, and numbers) are invariant from preschoolers to college students. Age $\times$ retention interval interactions generally are not found either when the procedure involves discrete trials, that is, when study and test trials are separate (Fajnsztejn-Pollack, 1973; Hasher \& Thomas, 1973; Kagan, Klein, Haith, \& Morrison, 1973; Nelson, 1971; Sophian \& Perlmutter, 1980), or when a continuous recognition task is used, that is, when study and test trials are intermixed (Berch \& Evans, 1973; Wagner, 1978; Wickelgren, 1975). Whether forgetting rates for contextual information are also age invariant is not yet known. No such prior studies could be located.

The results also touch on the issue of multidimensional forgetting. Evidence for differential forgetting of different types of information in a memory trace exists, although it is mixed. Several studies with adults, for example, have found that memory for semantic and for contextual features falls away at different rates (Bregman, 1968; Cermak \& Youtz, 1976; Jones, 1979; Kolers \& Ostry, 1974). There is also a study with infants that suggests that various types of information may be lost from memory at different rates (Strauss \& Cohen, cited in Kail, 1979). Other experiments with adults, however, have failed to distinguish differential forgetting rates (Jacoby, 1974; Shulman, 1970). Whether information about presentation modality is lost at a faster rate than semantic information is not yet known. The question is important because of theoretical concerns about the type of processing involved. If semantic features are processed to a deeper or wider 
level than physical features of words, as has been suggested by Craik and Lockhart (1972) and Craik and Tulving (1975), then differences in rates of decay would be expected.

Finally, the studies deal with the theoretical distinction between automatic and effortful memory processing. As proposed by Hasher and Zacks (1979), automatic encoding is characterized by age invariance, is not affected by an intention to learn, and does not interfere with other processing going on at the same time, among other criteria. Effortful processing, on the other hand, should be affected by manipulations within each of these criteria. Experimental evidence, in fact, suggests that presentation modality is processed automatically by both children and young adults. Lehman (1982), for example, found support in these age groups for all three Hasher and Zacks automaticity criteria listed above.

Recently, the emphasis has shifted from identifying automatically encoded attributes to comparing automatic and effortful memory tasks on various dimensions within the same subjects (Attig, 1983). This shift in strategy has been necessitated by concern with the adequacy of age invariance as a criterion for automatic processing (Burke \& Light, 1981) and by questions about the usefulness of the automatic/effortful distinction itself (Pezdek, 1983). The present studies extend previous work by providing an opportunity to demonstrate age invariance on a different dimension (e.g., forgetting rates) and by looking for different patterns of performance on tasks hypothesized to be automatic (e.g., modality identification) and effortful (e.g., word recognition).

A continuous mixed-modality recognition task based on one designed by Kirsner (1974) was employed in order to minimize the influence of age-related mnemonic strategies and to generate enough data points for retention functions to be drawn (Berch, 1975). In Experiment 1, thirdand fourth-grade children and college students were presented with a continuous series of 200 nouns, half of which were seen and half heard, and asked to judge whether each word was "new" or "old" and, if "old," whether it appeared in the "same" or in a "different" modality as before. A final recognition test was also administered either immediately or after $4 \mathrm{~h}, 1$ day, or 7 days. In Experiment 2, a change was made in the presentation of the visual stimuli to college students in order to clarify a question about modality effects that arose in Experiment 1 . The long-term test occurred either immediately or after 1 day.

\section{EXPERIMENT 1}

\section{Method}

\section{Subjects}

Forty-two third- and fourth-grade children who were attending suburban schools and summer camps were tested in Experiment 1. Ten of these children were subsequently eliminated from the sample because they failed to meet two performance criteria. Either they did not obtain a hit rate for modality information of at least .75 at lag 0 on the immediate test $(n=4)$, or they failed to correctly recognize at least seven old words on the long-term test $(n=6$ in the 4-h, 1-day, and 7-day delay groups). Both criteria most likely reflect motivational and/or attentional differences rather than memory deficits, since these errors tended to appear when clearly heard activity changes were occurring in the children's classroom (e.g., children preparing for swimming or hiking). The second criterion also ensured a large enough word-recognition base from which to examine modality-identification rates. Most of the children who did not meet this criterion simply said "new" to each word as soon as it was presented.

The final sample of 32 children was divided into four groups; each group comprised 4 males and 4 females, as well as an approximately equal number of third- and fourth-graders. The groups were assigned to different delay conditions: $0 \mathrm{~h}, 4 \mathrm{~h}, 1$ day, or 7 days. Preliminary analyses indicated no effects of grade level or of schools on either word recognition or modality identification for the immediate test.

In addition, 32 college students participated in the experiment in order to receive extra credit in introductory psychology courses. All of them met the two criteria discussed above. Both the 0-h and the 1-day delay groups were composed of 4 males and 4 females, and the 4-h and 7-day groups each contained 3 males and 5 females.

\section{Materials}

For the immediate test, a mixed-modality continuous recognition task of 200 words was constructed such that the second presentation of a word appeared after a lag of $0,5,10,25$, or 50. Eighty nouns from first- and second-grade readers were selected as "duplicates," that is, to be presented twice, and 40 nouns were chosen as "fillers," that is, to be presented only once here but tested subsequently on the long-term test. On the first presentation of the duplicate words, and on the occurrence of the filler words, half were presented visually and half auditorily. In addition, on the second presentation of the duplicate words, half occurred in the same and half in a different modality from their first appearance in the list. Thus, there were four modality conditions for duplicate words: auditory on both presentations (AA), visual on both presentations (VV), auditory first and then visual (AV), and visual followed by auditory (VA).

A predetermined sequence of words was used for all subjects. Each block of 50 words contained both fillers and duplicates in each lag $\times$ modality combination, with the exception of lag 50 , for which the first and second presentations necessarily occurred across blocks. Visually presented words were typed in orator-size print on $3 \times 5$ cards. Auditorily presented words were spoken by the experimenter while a blank $3 \times 5$ card was turned over. Each card remained in view until the subject had responded. Responses were generally made within 3 or $4 \mathrm{sec}$.

In order to assess long-term retention of the filler words from the immediate test, the 40 filler words were combined with 20 new nouns on a long-term recognition test. Half of the filler words were presented in the same modality and half in a different modality from their appearance on the immediate test. The new words were presented only once, half visually and half auditorily. Each word was presented individually on a card, as described above. The sequence was the same for all subjects. Each half of the long-term test contained an approximately equal number of filler words that had appeared on Trials 1 to 100 and on Trials 101 to 200 of the immediate test.

\section{Procedure.}

The subjects were tested individually on the immediate-retention test after a brief pretraining session with 12 words presented twice after lags of 0,2 , or 5 . Following a retention interval of $0 \mathrm{~h}$ (i.e., immediately after the continuous recognition test), $4 \mathrm{~h}, 1$ day, or 7 days, the subjects were again tested individually on the long-term 
recognition test. On all trials, the subjects were asked first to judge whether the word had been presented before (i.e. "old" or "new") and then, if it had been, whether the presentation modality was the same on both occasions. The participants were trained to respond "same," "different," or "new." On the long-term test, it was made clear that an "old" word was one that had been heard or seen 1 week (or 1 day, etc.) earlier.

\section{Results}

\section{Forgetting Rates}

Word recognition. The mean proportions of hits (correct "old" judgments) across lags are presented in Figure 1 separately for each age group and modality combination. Figure 1 includes the results for the five lags on the immediate test as well as the data for the long-term test averaged across the four delay groups. It suggests that, although adults may correctly recognize somewhat more words than do children, the rate of forgetting of this information is similar in both age groups. Whether words are presented auditorily first or visually first also does not appear to have an effect on forgetting rates.

In order to examine changes in performance over time, the hit rates were subjected to a 2 (age) $\times 6$ (lag) $\times 4$ (modality combination) analysis of variance. The major finding from this analysis was that the critical age $\times$ lag interaction was not statistically significant $[F(5,310)=$ 1.55 , n.s.], thus supporting the conclusion of comparable forgetting rates for words in children and adults. There was also no significant main effect of modality $[\mathrm{F}(3,186)$ $=2.04$, n.s.]. The analysis did, however, produce a statistically significant modality $\times$ lag interaction $[F(15,930)=5.38, p<.001]$, a significant main effect of lag $[F(5,310)=155.29, p<.001]$, and a significant main effect of age $[F(1,62)=7.26, p<.01]$. Simpleeffects analyses indicated that although modality differences occurred for particular lags (specifically, lags 5 , 25,50 , and long term), there was no overall generalizable pattern. Best recognition occurred sometimes for words presented visually first (either VV or VA) and

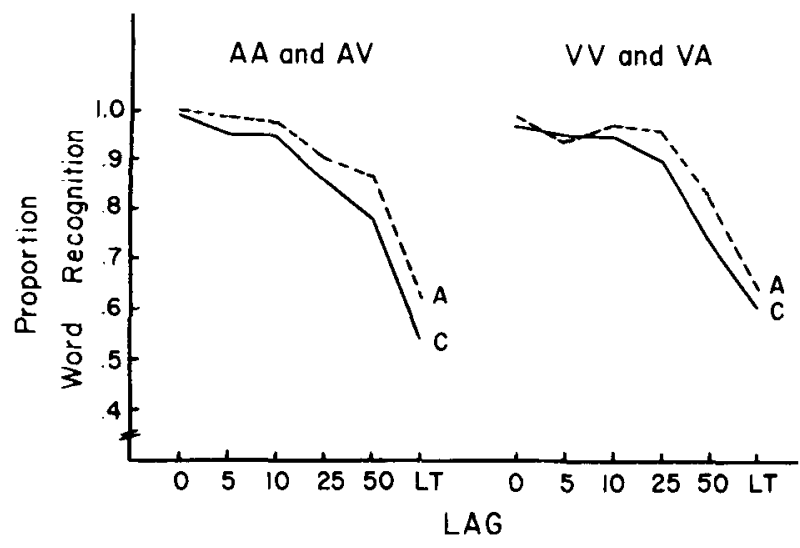

Figure 1. Experiment 1: Proportions of correct word recognition across lags for words presented anditorily first (AA \& AV) and visually first ( $V V \&$ VA) by children (C) and adults (A).
Table 1

Experiment 1: Word Recognition as a Function of Age

\begin{tabular}{lcccc}
\hline Age Group & Hits & False Alarms & $\mathrm{d}^{\prime}$ & $\beta$ \\
\hline Children & .849 & .041 & 2.79 & 2.67 \\
Adults & .890 & .091 & 2.58 & 1.15 \\
\hline
\end{tabular}

sometimes for words presented auditorily first (either AA or AV).

The small age difference in hit rates can be seen in Table 1, along with the false-alarm rates to the distractor words (i.e., incorrect "old" judgments), a measure of sensitivity $\left(\mathrm{d}^{\prime}\right)$, and a measure of response bias (B). The higher false-alarm rate of the adults suggests that their performance on word recognition might be artificially boosted by a tendency to respond "old." Indeed, when the $d^{\prime}$ scores were analyzed in a 2 (age) $\times 2$ (lag: immediate and long term) analysis of variance, the age difference disappeared $[F(1,62)=1.76$, n.s.]. This finding indicates that age differences in hit rates resulted primarily from the more conservative response criterion set by the children, rather than from any age change in memorytrace strength. The $\mathrm{d}^{\prime}$ analysis also corroborated two findings from the hit-rate analysis. Not only did performance decline across lags $[F(1,62)=164.24, p<.001]$, but it did so at a similar rate for both age groups $[F(1,62)$ $=1.20$, n.s.].

Finally, forgetting rates for words were investigated with linear trend analyses. When regressions were performed on the recognition proportions across six lags separately for children and adults, there were significant and similar declines at both ages. For children, $r=.91$, slope $=-.08, F(1,155)=307.01, p<.001$; for adults, $r=.86$, slope $=-.06, F(1,155)=314.64, p<.001$. Thus, the results clearly indicate that the rates of forgetting of words were highly comparable for the two age groups.

Modality identification. Conditional proportions of correct modality identification given word recognition were calculated in order to separate occurrence and modality judgments and to provide some control over agerelated differences in response bias. These conditional proportions are presented in Figure 2. The figure suggests that, although the rate of forgetting of modality information depends on whether the words were first heard or seen, these forgetting rates are remarkably similar in both children and adults.

A 2 (age) $\times 6$ (lag) $\times 4$ (modality combination) analysis of variance supported these suggestions. Neither the main effect of age nor the critical age $\times$ lag interaction was statistically significant ( $F<1$ in both cases). Performance did, of course, decrease across lags $[F(5,310)$ $=59.75, \mathrm{p}<.001]$ and was significantly worse when words were first presented auditorily $[F(3,186)=14.78$, $\mathrm{p}<.001]$. The means for each modality combination can be seen in Table 2. Tests on means using the NewmanKeuls procedure showed that both AA and AV differed from each of the visual-first conditions $(p<.05)$. In ad- 


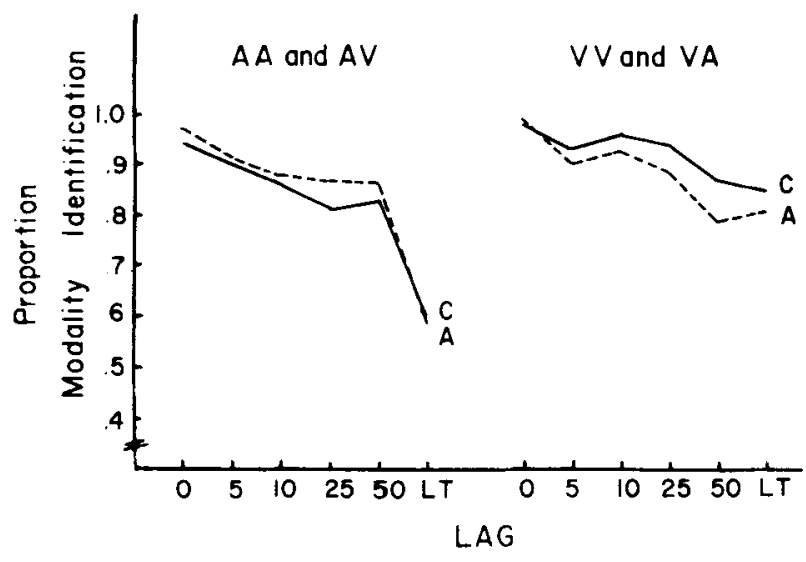

Figure 2. Experiment 1: Conditional proportions of correct modality identification, given word recognition, across lags for words presented auditorily first (AA \& AV) and visually first (VV \& VA) by children (C) and adults (A).

dition, the analysis of variance produced two statistically significant interactions: lag $\times$ modality $[\mathrm{F}(15,930)=$ $8.26, \mathrm{p}<.001]$ and age $\times$ modality $[\mathrm{F}(3,186)=3.22$, $\mathrm{p}<.05]$. Analysis of simple effects demonstrated that the decrease across lags in modality identification was greater in the auditory-first conditions than in the visualfirst conditions $[F(5,1240)=26.45, \mathrm{p}<.001$, for $\mathrm{AA}$; $\mathrm{F}(5,1240)=46.29, \mathrm{p}<.001$, for $\mathrm{AV} ; \mathrm{F}(5,1240)=$ $7.36, \mathrm{p}<.001$, for VA; and $\mathrm{F}(5,1240)=8.10, \mathrm{p}<$ .001 , for $\mathrm{VV}]$. The difference among modality conditions was especially noticeable in the long-term. Furthermore, the first-modality effect was greater for children than for adults $[\mathrm{F}(3,186)=15.80, \mathrm{p}<.001$, and $\mathrm{F}(3,186)=$ $2.26, \mathrm{p}<.10$, respectively]. These results held in further three-factor analyses of variance that first excluded lag 0 , then the long-term proportions, and finally both of these lags.

Comparable forgetting rates in the two age groups were also found in regression analyses. There were significant and similar declines at the two ages for words presented auditorily first (i.e., $\mathrm{AA}$ and $\mathrm{AV}$ ) [children, $\mathrm{r}=.87$, slope $=-.06, F(1,155)=68.22, p<.001 ;$ adults, $r=.82$, slope $=-.06, F(1,155)=123.91, p<.001]$ and for words presented visually first (i.e., VV and VA) [children, $\mathrm{r}=.88$, slope $=-.02, \mathrm{~F}(1,155)=32.20, \mathrm{p}<$ .001 ; adults, $r=.91$, slope $=-.04, F(1,155)=56.86$, $p<.001$ ]. Thus, the results indicate that information about whether a word is seen or heard is not forgotten faster by children than it is by adults.

Table 2

Experiment 1: Modality Identification (MI) as a Function of Modality Condition

\begin{tabular}{cccc}
\hline $\begin{array}{c}\text { Modality } \\
\text { Condition }\end{array}$ & $\begin{array}{c}\text { Conditional } \\
\text { MI Proportion }\end{array}$ & $\begin{array}{c}\text { False } \\
\text { Alarms }\end{array}$ & $\begin{array}{c}\text { True } \\
\text { MI Proportion }\end{array}$ \\
\hline AA & .81 & .020 & .81 \\
AV & .86 & .045 & .85 \\
VA & .89 & .034 & .89 \\
VV & .91 & .032 & .91 \\
\hline
\end{tabular}

There are two possible response biases that could affect the modality-identification data (Kirsner, 1974). First, performance might be improved by giving more "new" responses when uncertain about modality of first presentation. This bias could occur equally in both modalities, with the result that the modality-identification proportions in Figure 2 would overestimate the amount of information actually present, or it could occur in the visual modality only and thus produce artificially higher proportions for words presented visually first. Neither form of the bias was supported. Modality-identification proportions have been found to be similar whether adults are asked to judge both word and modality or whether they are asked simply to judge modality (Lehman \& Mellinger, 1984). In addition, in the present study, not only were there no overall differences among modality conditions on hit rates for words in the analysis of variance discussed above, but there were also identical false-alarm rates to new words presented auditorily or visually (false-alarm rate $=.07$ in each case).

The second bias consists of giving more "same" responses to words in one or both modalities. This bias could partially produce the main effect of modality condition, that is, lowest modality identification in the AA condition and highest in VV (see Table 2), if there were a tendency to report "different" for auditorily presented words and "same" for visually presented words. In fact, $68 \%$ of children's and adults' false alarms to new auditory words were "different," whereas only $52 \%$ of their false alarms to new visual words were "different." Since there was some evidence for the bias, "true" proportions of modality identification were estimated by using the standard correction for guessing, $[\mathrm{P}($ hits $)-\mathrm{P}($ false alarms $)] /[1-P$ (false alarms) $]$. Table 2 presents the falsealarm rates that were calculated from the allocation of "same" and "different" judgments to new words. As an example, the false-alarm rate for the VV condition equaled the number of "same" judgments given to new visually presented words. The "true" proportions, which can also be seen in Table 2, indicate that the calculation made little change in the overall advantage associated with the visual-first conditions.

Finally, memory for words was compared with memory for input mode in a 2 (age) $\times 6$ (lag) $\times 2$ (attribute) analysis of variance. The most interesting finding from this analysis was the statistically significant lag $X$ attribute interaction $[F(5,310)=20.24, p<.001]$. As can be seen in the left panel of Figure 3, the decay functions for words and their presentation modalities differed. Wordrecognition accuracy stayed high initially, but then dropped off quickly after lag 25. Modality identification, on the other hand, began decreasing early, but did so at a slower rate. The net effect was that memory for modality was better than memory for words in the long term. These patterns held for both children and adults.

\section{Long-Term Retention}

Word recognition. The mean proportions of correct word recognition for each long-term delay are presented 


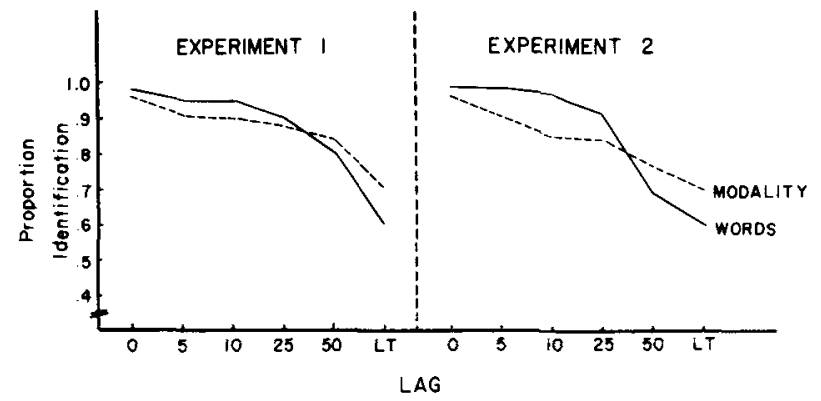

Figure 3. Proportions of correct word recognition and modality identification (given word recognition) across lags.

in the left half of Table 3 . Since there were no statistically significant differences among delay groups on immediate-memory word recognition in a 4 (delay) $\times 2$ (age) analysis of variance, a 2 (age) $\times 4$ (delay) $\times 2$ (modality combination) analysis of variance was performed directly on the long-term hit rates shown in Table 3. It revealed significant main effects of delay $[F(3,56)=6.49$, $\mathrm{p}<.01]$ and modality $[\mathrm{F}(1,56)=5.09, \mathrm{p}<.05]$, and a significant age $\times$ delay interaction $[F(3,56)=3.58$, $\mathrm{p}<.05]$. Overall, fewer words were correctly recognized as "old" as the delay increased, and performance was slightly better for words presented visually first. Analysis of simple effects showed that the difference between ages reached significance only for the 7-day delay group $[F(1,56)=9.65, p<.01]$, in which adults had higher hit rates than children. This age difference was probably due to the more conservative response bias of the children. Adults had higher false-alarm rates in long-term memory than did children (.20 and .10, respectively). In addition, when the $d^{\prime}$ long-term recognition scores were analyzed in a 4 (delay) $\times 2$ (age) analysis of variance, neither the main effect of age nor the age $x$ delay interaction was statistically significant $[F(1,56)=3.48$, n.s., and $F<1$, respectively]. Finally, a separate 2 (trials on immediate memory) $\times 2$ (age) analysis of variance showed that long-term hit rates were higher for words that had been presented in the second half of the immediate test $[F(1,62)=9.81, p<.01]$. This finding was true for both children and adults.
Long-term word-recognition proportions were also investigated by comparing them with chance performance. A guessing rate of .5 was used, since the subject's first decision about a word was whether it was "new" or "old." Retention of information about whether or not a word had been presented before (combined across modalities) was above chance in children only at 0 and $4 \mathrm{~h}$ $[t(7)=3.96, p<.01$, and $t(7)=2.56, p<.025$, respectively]. The adults' overall performance was above chance at $0 \mathrm{~h}$ and 1 day $[\mathrm{t}(7)=6.39, \mathrm{p}<.01$, and $\mathrm{t}(7)=2.48$, $\mathrm{p}<.025$, respectively].

Modality identification. The mean proportions of correct long-term modality identification, given word recognition, are presented in the right half of Table 3 separately for each delay group. Although these conditional proportions suggest that first modality rather than age is the critical factor in the decline in performance over the long term, the proportions themselves cannot be compared in an analysis of variance because of some differences in modality identification among the four delay groups on the immediate test. When immediate memory was analysed in a 4 (delay) $\times 2$ (age) $\times 2$ (modality) analysis of variance, the delay $\times$ modality interaction was statistically significant $[F(3,56)=4.44, p<.01]$. Therefore, a threefactor analysis of variance was performed on the difference scores between immediate and long-term retention. This analysis produced two significant main effects, modality and delay group, and two significant interactions, modality $\times$ delay and age $\times$ delay $[\mathrm{F}(1,56)=47.87$, $\mathrm{p}<.001, \mathrm{~F}(3,56)=18.77, \mathrm{p}<.001, \mathrm{~F}(3,56)=11.69$, $\mathrm{p}<.001$, and $\mathrm{F}(3,56)=3.44, \mathrm{p}<.05$, respectively]. Analysis of simple effects showed that the drop in modality identification across long-term delays occurred for conditions in which words were heard first, but not for conditions in which words were seen first $[F(3,112)=$ $30.40, \mathrm{p}<.001$, and $\mathrm{F}<1$, respectively]. In addition, significant age differences occurred only at the 7-day interval, for which the drop for children was greater than the drop for adults $[F(1,56)=6.01, p<.05]$. Finally, a separate analysis of variance demonstrated that where a word had been presented on the immediate test, that is, in the first or second half of the test, had no effect on long-term modality identification.

Table 3

Experiment 1: Long-Term Retention of Words and Their Presentation Modalities

\begin{tabular}{|c|c|c|c|c|c|c|}
\hline \multirow[b]{2}{*}{ Age/Delay Group } & \multicolumn{3}{|c|}{ Word Recognition } & \multicolumn{3}{|c|}{ Modality Identification } \\
\hline & AA \& AV & VV \& VA & Combined & $A A \& A V$ & VV \& VA & Combined \\
\hline \multicolumn{7}{|l|}{ Children } \\
\hline 0 hour & .68 & .76 & .72 & .73 & .89 & .81 \\
\hline 4 hours & .62 & .69 & .65 & .82 & .85 & .84 \\
\hline 1 day & .50 & .56 & .53 & .56 & .84 & .70 \\
\hline 7 days & .36 & .38 & .37 & .24 & .81 & .53 \\
\hline \multicolumn{7}{|l|}{ Adults } \\
\hline 0 hour & .74 & .72 & .73 & .76 & .87 & .81 \\
\hline 4 hours & .57 & .53 & .55 & .66 & .78 & .72 \\
\hline 1 day & .61 & .66 & .63 & .49 & .77 & .64 \\
\hline 7 days & .57 & .65 & .61 & .41 & .83 & .64 \\
\hline
\end{tabular}


Retention of modality information over the long term was well above chance even after 7 days for words that had been seen first. This was true for both children and adults. A value of .50 was again used as the guessing rate, since, once the decision "old" word had been made, the subjects had only two choices left (i.e., "same" or "different" modality). As can be seen in Table 3, the closest to chance for words that had been presented visually first was the 1-day group of adults. This observed proportion of .77 was reliably greater than chance $[\mathrm{t}(7)$ $=3.40, p<.01]$. All of the other observed proportions for words presented visually first also exceeded chance (all at $p<.005$ ). Remembering that information had been presented auditorily first, on the other hand, was better than chance only up to $4 \mathrm{~h}$. For adults at $0 \mathrm{~h}, \mathrm{t}(7)=4.57$, $\mathrm{p}<.005$, and at $4 \mathrm{~h}, \mathrm{t}(7)=2.59$, p < .025; for children at $0 \mathrm{~h}, \mathrm{t}(7)=2.86, \mathrm{p}<.025$, and at $4 \mathrm{~h}, \mathrm{t}(7)=$ $10.41, \mathrm{p}<.005$.

\section{EXPERIMENT 2}

The main concern in Experiment 2 was whether the more accurate identification of modality that occurred in Experiment 1 for words that had been presented visually first was due to the somewhat longer exposure of the visually presented words.

\section{Method}

\section{Subjects}

Of the 17 college students who were tested in Experiment 2, one was eliminated from the sample because he did not meet the criterion for word-recognition hit rate at lag 0 on the immediate test (i.e., .75 ). The remaining 16 subjects were divided into two groups, a 0 -h delay group and a 1-day delay group, with each group comprising 2 males and 6 females. All subjects received extra credit for research participation in their introductory psychology courses.

\section{Procedure}

The procedure in Experiment 2 was the same as that in Experiment 1, with one exception. In Experiment 1, the cards, and thus the visually presented words, remained visible until a response had been made. In Experiment 2, on the other hand, the cards were turned over, the subjects either heard or saw a word, and, after $2 \mathrm{sec}$ the cards were removed whether or not the response had yet been made.

\section{Results}

The data clearly show that the procedural change introduced in this study had no effect on the results. The proportions of correct modality identification on the immediate test were .82 for words presented auditorily first and .92 for words presented visually first. On the longterm test, the proportions were .54 and .85 . A detailed presentation of the hit rates for word recognition and for modality identification conditionalized on word recognition appears in Table 4.

\section{Forgetting Rates}

Word recognition. When a three-factor analysis of variance was performed on the hit rates summarized in Table 4 , both the main effect of lag and the three-way interaction (delay group $\times$ lag $\times$ modality combination) were statistically significant $[\mathrm{F}(5,70)=32.93, \mathrm{p}<.001$, and $F(5,70)=2.45, p<.05$, respectively]. No main effect of modality condition appeared, however $[F(1,14)$ $=2.19$, n.s.]. Thus, word recognition clearly declined across lags, and there was no overall effect of whether a word was first presented auditorily or visually. The three-way interaction occurred because, for the 1-day group, hit rates were higher at lag 4 for words presented visually first, whereas at lag 5 , they were higher for words presented auditorily first.

This group of adults had even lower false-alarm rates to new words than did the adults in Experiment 1. They made only 116 errors over 2,240 responses (140 new words presented to 16 subjects), for a false-alarm rate of .052 . They were, however, slightly more likely to judge a new word as being "old" when it was presented auditorily than when it appeared visually. These false-alarm rates were .056 and .047 , respectively. In addition, there was a strong bias to report "different" when a word was

Table 4

Experiment 2: Immediate and Long-Term Retention of Words and Their Presentation Modalities

\begin{tabular}{|c|c|c|c|c|c|c|}
\hline \multirow[b]{2}{*}{ Delay Group } & \multicolumn{3}{|c|}{ Word Recognition } & \multicolumn{3}{|c|}{ Modality Identification } \\
\hline & $\mathrm{AA} \& \mathrm{AV}$ & VV \& VA & Combined & $\mathrm{AA} \& \mathrm{AV}$ & VV \& VA & Combined \\
\hline \multicolumn{7}{|l|}{0 Hour } \\
\hline $\mathrm{Lag} 1$ & 1.00 & .97 & .98 & .94 & .98 & .96 \\
\hline 2 & .98 & .97 & .98 & .84 & .96 & .90 \\
\hline 3 & .97 & .97 & .97 & .77 & .92 & .85 \\
\hline 4 & .98 & .92 & .95 & .78 & .90 & .84 \\
\hline 5 & .77 & .73 & .75 & .70 & .77 & .75 \\
\hline LT & .72 & .65 & .68 & .79 & .77 & .81 \\
\hline \multicolumn{7}{|l|}{1 Day } \\
\hline Lag 1 & 1.00 & .97 & .98 & .95 & .95 & .95 \\
\hline 2 & 1.00 & .97 & .98 & .86 & .97 & .91 \\
\hline 3 & .98 & .94 & .96 & .78 & .93 & .85 \\
\hline 4 & .81 & .95 & .88 & .68 & .96 & .84 \\
\hline 5 & .69 & .58 & .63 & .86 & .72 & .79 \\
\hline $\mathrm{LT}$ & .53 & .52 & .53 & .28 & .92 & .60 \\
\hline
\end{tabular}


heard (64\% of false alarms to new auditory words) and "same" when a word was seen $(87 \%$ of false alarms to new visual words).

Modality identification. A three-factor analysis of variance on the modality-identification conditional proportions shown in Table 4 produced two statistically significant main effects and three statistically significant interactions. It was clear that the first-modality effect was replicated. Overall, modality identification was higher for words presented visually first $[F(1,14)=14.18, p<$ $.01]$, and, as expected, performance decreased across lags $[F(5,70)=18.60, p<.01]$, especially for the 1-day group $[\mathrm{F}(5,70)=3.55, \mathrm{p}<.01]$. In addition, modality condition interacted with lag $[\mathrm{F}(5,70)=4.82, \mathrm{p}<.01]$ and with delay group $\times \operatorname{lag}[F(5,70)=7.20, p<.01]$. The significant three-way interaction indicates that modality identification decreased more across lags for AA and $A V$ than for VV and VA and that the difference was more noticeable in the long term, especially after a 1-day delay.

A 6 (lag) $\times 2$ (attribute) repeated-measures analysis of variance was also carried out on the proportions shown in the right panel of Figure 3. The main effect of lag and the interaction between lag and attribute were statistically significant $[\mathrm{F}(5,75)=37.27, \mathrm{p}<.001$, and $\mathrm{F}(5,75)=$ $6.89, p<.001$, respectively]. Thus, the differential decay functions for words and their presentation modalities observed in Experiment 1 were also present in Experiment 2.

\section{Long-Term Retention}

Long-term word recognition (see Table 4) was above chance only at $0 \mathrm{~h}[\mathrm{t}(7)=2.99, \mathrm{p}<.025]$. This was true whether words were seen first or heard first. On the other hand, retention of modality information over the long term was well above chance even after 1 day for words that had been presented visually first $[\mathrm{t}(7)=3.63$, $\mathrm{p}<.005$, at $0 \mathrm{~h}$, and $\mathrm{t}(7)=13.07, \mathrm{p}<.001$, at 1 day $]$. When words were presented auditorily first, however, identification of modality was better than chance only at $0 \mathrm{~h}[\mathrm{t}(7)=3.74, \mathrm{p}<.005]$.

\section{DISCUSSION}

The results provide further evidence that long-term memory representations in both children and adults contain a great deal of information about input mode. They demonstrate that information about whether a word was seen or heard remains in memory for at least $4 \mathrm{~h}$ and that some types, for example, knowledge that a word was presented visually, may remain in memory for as many as 7 days. They also clearly show that this information is not lost more rapidly by children than by adults. Forgetting rates for modality identification were invariant from middle childhood to young adulthood. These decay functions were affected, however, by the initial input mode, with modality identification declining more rapidly for words heard first than for words seen first.

Age invariance in forgetting rates for contextual information was not entirely unexpected. Previous develop- mental studies of the forgetting of words (i.e., semantic information) have not reported the critical age $x$ lag interaction (e.g., Wickelgren, 1975), a finding that was corroborated in the present experiments. In addition, in developmental studies of memory for presentation modality, no age changes across childhood have been found on tasks that take about $.5 \mathrm{~h}$ to complete (e.g., Lehman \& Hanzel, 1981). The present studies extended the retention interval up to 7 days and still found no evidence for differential forgetting rates for information about input mode in children and adults.

The effect of the initial modality of presentation on modality identification was unexpected, however. Kirsner (1974), using a similar continuous recognition task with adults, reported better performance for the intramodality conditions and concluded that the advantage resulted from the subjects' tendency to give more "same" than "different" responses. When this response bias was taken into account, the overall advantage associated with the intramodality conditions was eliminated. In the present experiments, an advantage was associated with words that were presented visually first, regardless of the modality in which the second presentation of a word occurred. This effect was not due to longer exposures of the visually presented material, since the result held even in Experiment 2 , in which exposure rates were controlled. It could only partially be explained by response bias. The subjects did have a tendency to report "different" for auditorily presented words and "same" for visually presented words (i.e., to think the words were seen), especially in Experiment 2, but this bias would still not account for the higher modality identification in the VA condition than in either the AA or the AV condition.

One possible explanation for this initial-modality effect on modality identification is that visual input tends to dominate other modalities. Posner and Nissen (1976) suggested that subjects show an attentional bias toward the visual modality because visual stimuli are not as alerting as stimuli in other modalities. Fewer differences might then be expected for this more highly demanding activity than for a less demanding activity, such as one involving audition (cf. Kausler \& Hakami, 1983). Alternatively, a dual-encoding hypothesis (e.g., Paivio, 1971) may account for the finding that modality identification was higher for words presented visually first. Written concrete words may be represented in both the imaginal and the verbal systems, thus providing two avenues of access, whereas spoken words may be represented only in the verbal system. Evidence that the incidental properties of visually presented words, such as their presentation modality, are retained through mental images does, in fact, exist. Light and Berger (1976) reasoned that if visual attributes are retained as images, then memory for the various attributes should be correlated. In two studies now, modality and semantic information have been found to be related in memory when words were presented visually. No relationship appeared, however, when the words occurred auditorily (Hintzman et al., 1972; Lehman, 1982).

The results also provide several examples of different 
patterns of performance for words and their presentation modalities. The most obvious difference occurred in the forgetting rates. Whereas information about modality tended to decline gradually with time, word recognition remained high initially and then declined more rapidly, even to a point at which memory for modality was better than memory for words. This finding of differential forgetting of semantic and modality information lends support to attempts to demonstrate that different types of information may be lost from memory at different rates (e.g., Jones, 1979). However, in its demonstration that modality information is not always lost more rapidly than semantic information, the finding questions the levels-ofprocessing idea (Craik \& Lockhart, 1972) that physical features of words are processed to a "shallower" level than semantic features and/or that the "deep" processing of semantic information produces a more durable memory trace.

A second difference between the two types of codes was that the initial modality of presentation had an effect on modality identification, but not on word recognition. If, as discussed above, imagery is used for written concrete words, then Hasher, Riebman, and Wren's (1976) conclusion that imagery does not result in superior long-term retention of semantic information may help to explain the lack of an effect on word recognition. Finally, a third difference was that whether a word was presented in the first or second half of the immediate test had an effect on long-term word recognition but not on long-term modality identification. Long-term hit rates were higher for words that had been presented in the second half of the immediate test.

Taken together, these differences demonstrate that information about input mode is processed differently from information about the meaning of words. One processing dimension that has been implicated in prior research is the automatic/effortful distinction (e.g., Lehman, 1982). The results of the present studies suggest that it would be fruitful to pursue this theoretical distinction in future research endeavors.

\section{REFERENCES}

AtTIG, M. S. (1983, August). Recent research on automaric and effortful memory processing: The effect of subject variables. Paper presented at the meeting of the American Psychological Association, Anaheim, CA.

BERCH, D. B. (1975). Methodological problems in the study of memory development: A critique of the Perlmutter and Myers experiment. Bulletin of the Psychonomic Society, 6, 285-286

BERCH, D. B., \& EVANS, R. (1973). Decision processes in children's recognition memory. Journal of Experimental Child Psychology, 16, 148-164.

BRAY, N. W. BATChELDER, W. H. (1972). Effects of instructions and retention interval on memory of presentation mode. Journal of Verbal Learning and Verbal Behavior, 11, 367-374.

Bregman, A. S. (1968). Forgetting curves with semantic, phonetic, graphic, and contiguity cues. Journal of Experimental Psychology, 78, 539-546.

Burke, D. M., \& Light, L. L. (1981). Memory and aging: The role of retrieval processes. Psychological Bulletin, 90, 513-546.

Cermak, L. S., \& Youtz, C. P. (1976). Retention of phonemic and semantic features of words. Memory \& Cognition, 4, 172-175.
CRAIK, F. I. M. , \& LoCKHART, R. S. (1972). Levels of processing: A framework for memory research. Journal of Verbal Learning and Verbal Behavior, 11, 671-684

Craik, F. I. M., \& Tulving, E. (1975). Depth of processing and the retention of words in episodic memory. Journal of Experimental Psychology. General, 104, 268-294.

FAJNSZTEJN-PollaCK, G. (1973). A developmental study of decay rate in long-term memory. Journal of Experimental Child Psychology, 16. 225-235.

HASHer, L., RiebmaN, B., \& Wren, F. (1976). Imagery and the retention of free-recall learning. Journal of Experimental Psychology: Human Leaming and Memory, 2, 172-181.

Hasher, L., \& Thomas, H. (1973). A developmental study of retention. Developmental Psychology, 9, 281.

HASHER, L., \& ZACKS, R. T. (1979). Automatic and effortful processes in memory. Journal of Experimental Psychology: General, 108, 356-388.

Hintzman, D. L., Block, R. A., InSkeep, N. R. (1972). Memory for mode of input. Journal of Verbal Learning and Verbal Behavior, 11 , $741-749$

JACOBY, L. L. (1974). The role of mental contiguity in memory: Registration and retrieval effects. Joumal of Verbal Learning and Verbal Behavior. 13, 483-496.

JoNES, G. (1979). Multirate forgetting. Joumal of Experimental Psychology: Human Learning and Memory, 5, 98-114.

Kagan, J., Klein, R., Haith, M., \& Morrison, F.(1973). Memory and meaning in two cultures. Child Development, 44, 221-223.

KAIL, R. (1979). The development of memory in children. San Francisco Freeman.

Kausler, D. H. \& Hakami, M. K. (1983). Memory for activities: Adult age differences and intentionality. Developmental Psychology, 19, 889-894

KIRSNER, K. (1974). Modality differences in recognition memory for words and their attributes. Journal of Experimental Psychology, 102, 579-584

KOLERS, P. A. (1975). Memorial consequences of automatized encoding. Journal of Experimental Psychology: Human Learning and Memon: 1. 687-701

Kolers, P.A. (1976). Reading a year later. Journal of Experimental Psychology: Human Learning and Memory, 2, 554-565.

Kolers, P.A., \& OSTRY, D. J. (1974). Time course of loss of information regarding pattern analyzing operations. Joumal of Verbal Learning and Verbal Behavior, 13, 599-612.

LEHMAN, E. B. (1982). Memory for modality: Evidence for an automatic process. Memory \& Cognition, 10, 554-564.

LEHMAN, E. B., \& HANZEL, S. H. (1981). A developmental study of memory for presentation modality. Journal of General Psychology, 105, 155-164

LEHMAN, E. B. . \& MEllinger, J. C. (1984). The effects of aging on memory for presentation modality. Developmental Psychology, 20, 1210-1217.

LIGHT, L. L., \& BERGER, D. E. (1976). Are there long-term "literal co pies'" of visually presented words? Joumal of Experimental Psychology Human Learning and Memory , 2, 654-662.

MadigAN, S., DoherTy, L. (1972). Retention of item attributes in free recall. Psychonomic Science, 27, 233-235.

NeLSON, K. C. (1971). Memory development in children: Evidence from nonverbal tasks. Psychonomic Science, 25, 346-348.

PaIvio, A. (1971). Imagery and verbal processes. New York: Holt, Rinehart \& Winston.

Pezdek, K. (1983). Memory for items and their spatial locations by young and elderly adults. Developmental Psychology, 19, 895-900.

PosNer, M. I., \& NissEN, M. J. (1976). Visual dominance: An informationprocessing account of its origins and significance. Psychological Review. 83, $157-171$.

Shulman, H. G. (1970). Encoding and retention of semantic and phonemic information in short-term memory. Joumal of Verbal Learning and Verbal Behavior, 9, 499-508.

Sophian, C., \& Perlmutter, M. (1980). Encoding and retention factors in the early development of recall. Bulletin of the Psychonomic Society, 15, 342-344.

Wagner, D. A. (1978). Memories of Morocco: The influence of age, schooling, and environment on memory. Cognitive Psychology, 10, 1-28

Wickelgren, W. A. (1975). Age and storage dynamics in continuous recognition memory. Developmental Psychology, 11, 165-169.

(Manuscript received July 2, 1984:

revision accepted for publication December $27,1984$. ) 